\section{The Rise of One-Person Households}

Socius: Sociological Research for a Dynamic World

Volume 7: I-3

(C) The Author(s) 2021

Article reuse guidelines:

sagepub.com/journals-permissions DOI: $10.1177 / 23780231211062315$ srd.sagepub.com

@SAGE

\section{Philip N. Cohen' ${ }^{\prime}$ (iD}

\begin{abstract}
In this visualization, the author shows the trend in the proportion of households that comprise only one person in 75 countries, representing 73 percent of the world's population, using national data collected between 1960 and 2019. At the time of the latest observations for each country, the percentage of households that include only one person ranges from 2.6 (Cambodia) to 38 (Switzerland). Europe and the United States have the highest solo living rates, along with two African countries (South Africa and Botswana, both severely affected by the HIVIAIDS epidemic), Israel, Jamaica, and Puerto Rico. In all, 53 of the 75 countries exhibit increases in one-person households, including all European countries. Those with (generally much smaller) declines are disproportionately in Africa and Asia, including China and India.
\end{abstract}

\title{
Keywords
}

households, demography, data visualization

The rise of living alone reflects later marriage and nonmarriage, delayed childbearing and childlessness, higher divorce rates, living-apart-together relationships, longer life spans, and widowhood - and a growing desire for individual autonomy and independence. Living alone is most common among young adults and older adults, when people are not yet coupled or are divorced or widowed (Esteve et al. 2020). Inequality and social exclusion push some people toward life alone; but rising living standards also make it possible for people to avoid living with their families (Klinenberg 2013). Although all societies may be experiencing at least some of these trends, there is substantial variation in the pace and degree of change. For both cultural and economic reasons, wealthy societies have been leading these developments, but they are increasingly apparent among middle-income countries as well (Lesthaeghe 2014).

A comparison of one-person household prevalence is possible across a large number of societies, rich and poor, that have conducted national censuses and surveys since 1960 . Esteve et al. (2020) examined the rate of solo living around the world by age, using contemporary data. Ortiz-Ospina (2019) tracked the trend for almost all countries using United Nations data, Demographic and Health Surveys, and European state data.

In this visualization (Figure 1), I show the trend in the proportion of households that comprise only one person in 75 countries using national censuses (or, in a minority of cases, national surveys) only, collected between 1960 and
2019. To show trends, I include only countries that have at least two data points at least 10 years apart, with the latest observation in 2000 or later. These 75 countries represent 73 percent of the world's population in 2019. The figure is color coded to show countries by region (as defined by the World Bank), with panels sorted by the value of the latest observation.

The data were retrieved from the Integrated Public Use Microdata Series, International (Minnesota Population Center 2020). As I am estimating only one parameter, I did not need to use the full (very large) data set from every country, so instead I drew a sample of 50,000 households from each census or survey (fewer were available in some cases) and used household or person weights where available. For the United States, I added data from the American Community Survey for 2019, as it was not yet part of the international data collection. Puerto Rico is in the data set as a separate country. Codebooks, Stata code to compile the data, R code to generate the figure, and the final data set are available at https://osf.io/wkpa5/.

In the latest observations for each country, the percentage of households that include only one person ranges from 2.6 in

\footnotetext{
'University of Maryland, College Park, MD, USA

Corresponding Author:

Philip N. Cohen, University of Maryland, 2112 Art-Sociology Building, College Park, MD 20742, USA

Email: pnc@umd.edu
} 


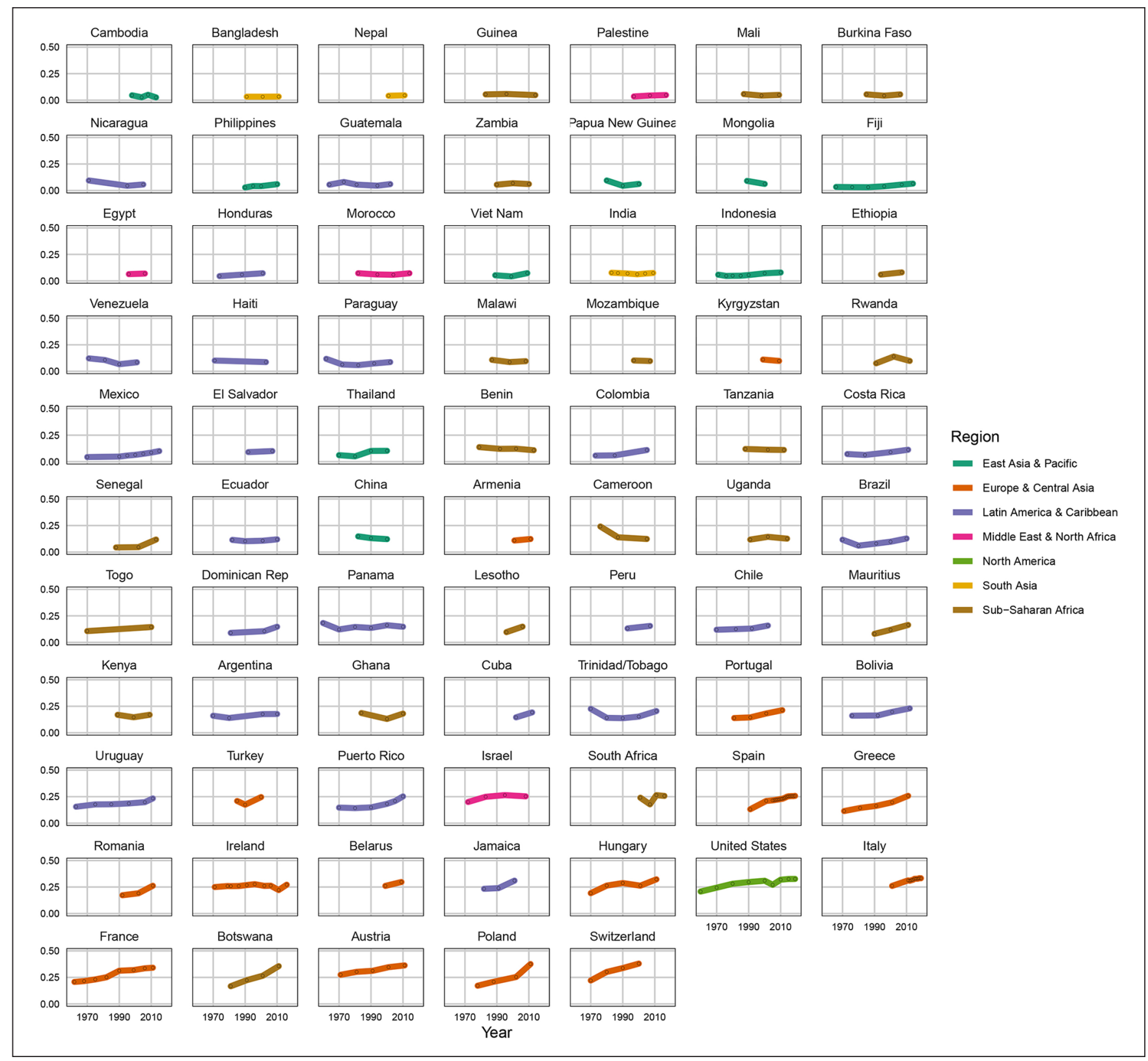

Figure I. One-person households as a proportion of all households, by country: selected dates, 1960 to 2019.

Source: The Integrated Public Use Microdata Series (IPUMS), International, collection of census microdata from the Minnesota Population Center (2020). Note: One-person households are from the number of household members, which is listed for every household in the sample. Countries are included if they have at least two censuses or surveys in the collection, at least 10 years apart, with the latest one conducted after 2000 . The sample is 50,000 households from each census or survey (or fewer in a small number of cases in which that many were not available), using household or person weights where available. In most cases the data are from complete censuses, but some are from national surveys in place of censuses. See IPUMS documentation at the source for details. The U.S. data include the American Community Survey for 2019, which was not part of the IPUMS collection. Puerto Rico is in the data set as a separate country.

Cambodia to 38 in Switzerland. Seventeen countries have more than 25 percent solo households, most of them in Europe or North America. The two African countries with high oneperson prevalence, South Africa and Botswana, are among the most severely affected by the HIV/AIDS epidemic. Israel, Jamaica, and Puerto Rico are above 25 percent as well. In all,
53 of the 75 countries exhibit rising one-person prevalence (including all included European countries). Those with declines are disproportionately in Africa and Asia and show much smaller changes (including China and India). Two additional figures are in the supplemental file, showing the rate of change in each country and the trends grouped by region. 
This visualization captures the concentration of one-person households in wealthy societies but also those with cultural traits or demographic idiosyncrasies that lead to living alone. Although widely prevalent, the rise of one-person households is not universal, as evident in China and India. Studying this pattern is important for understanding the relationship between families and social change.

\section{ORCID iD}

Philip N. Cohen (iD https://orcid.org/0000-0003-2839-3144

\section{Supplemental Material}

Supplemental material for this article is available online.

\section{References}

Esteve, Albert, David S. Reher, Rocío Treviño, Pilar Zueras, and Anna Turu. 2020. "Living Alone over the Life Course: CrossNational Variations on an Emerging Issue." Population and Development Review 46(1):169-89.

Klinenberg, Eric. 2013. Going Solo: The Extraordinary Rise and Surprising Appeal of Living Alone. New York: Penguin.
Lesthaeghe, Ron. 2014. "The Second Demographic Transition: A Concise Overview of Its Development." Proceedings of the National Academy of Sciences 111(51):18112-15.

Minnesota Population Center. 2020. "Integrated Public Use Microdata Series, International: Version 7.3." Minneapolis: Minnesota Population Center.

Ortiz-Ospina, Esteban. 2019. "The Rise of Living Alone: How One-Person Households Are Becoming Increasingly Common around the World." Our World in Data. Retrieved September 27, 2021. https://ourworldindata.org/living-alone.

\section{Author Biography}

Philip N. Cohen is a professor of sociology at the University of Maryland, College Park. His research concerns the demography of families and inequality. He is the author of The Family: Diversity, Inequality, and Social Change (W. W. Norton, 2021) and Enduring Bonds: Inequality, Marriage, Parenting, and Everything Else That Makes Families Great and Terrible (University of California Press, 2018). He is the director of SocArXiv, an open archive for the social sciences; a member of the General Social Survey Board of Overseers; a former coeditor of Contexts; and a former chair of the American Sociological Association Family Section. His current book project is titled Citizen Scholar. 